\title{
Identification of endophytic fungi from the medicinal plants of Biligirirangana hill, Karnataka
}

\author{
K. S. Sushma* \\ Department of Studies and Research in Microbiology, Mangalore University, Post \\ Graduate Centre Jnana Kaveri Campus Kodagu-571232, Karnataka, India

\section{Jayashankar} \\ Department of Studies and Research in Microbiology, Mangalore University, Post \\ Graduate Centre Jnana Kaveri Campus Kodagu-571232, Karnataka, India
}

A. K. Vinu

Department of Studies and Research in Microbiology, Mangalore University, Post Graduate Centre Jnana Kaveri Campus Kodagu-571232, Karnataka, India

Mohammed Ali Saeed

Department of Studies and Research in Microbiology, Mangalore University, Post Graduate Centre Jnana Kaveri Campus Kodagu-571232, Karnataka, India

*Corresponding author. E-mail: ksushmitha80@gmail.com

\begin{abstract}
Four plants with medicinal properties Carica papaya, Phyllanthus amarus, Tinospora cordifolia and Azadiracta indica were selected as a host plant for the isolation of endophytic fungi collected from Biligirirangana Hill, ranges from $11^{\circ} 40^{\prime}$ to $12^{\circ} 09^{\prime}$ North and $77^{\circ} 05^{\prime}$ to $77^{\circ} 01^{\prime}$ East, the southern part of Eastern Ghats Chamarajanagar District, Karnataka. The leaves of these plants revealed two, four, six and three isolates of endophytic fungi which belonged to the family Hypomycetes, Ascomycetes, Dothideomycetes, Coleomycetes respectively. One of the unidentified strain from each of the above four medicinal plant isolate was subjected to molecular analysis followed by $18 \mathrm{SrRNA}$ sequence, internal transcribed spacer regions and phylogenetic analysis. Based on the gene sequencing and phylogenetic tree the clusters species of the fungal isolate was found to be Stemphylium lycopersici, Epicoccum nigrum, Leptosphaerulina arachidicola and Phomopsis azadirachtae reported in this paper.
\end{abstract}

Keywords: Biligirirangana Hill, Endophytic fungi, Medicinal plants, Phylogenetic analysis, Sequencing

\section{INTRODUCTION}

Medicinal plants and their endophytes are the important resource of natural products. Traditionally herbal drugs are prescribed even today as they are effective, minimal side effects and relatively low cost (Valiathan, 1998). Microorganisms that lives inside the internal tissues of living plants colonizing inter and intracellular regions without any symptoms and causing no harm to the host plants is called endophyte (Schulz and Boyle, 2006). The endophytic interaction as not 'causing apparent harm' which refers to an absence of macroscopically visible symptoms. Endophytes form a symbiotic association with their host plant. The protection mechanism of the endophytes is exerted directly by releasing metabolites to attack any antagonists and promotes growth. It is believed in many cases that the microbes function as defense mechanism against phytopathogens. They play an essential role to provide protection

\section{Article Info}

DOI:10.31018/jans.v10i4.1890 Received: September 10, 2018 Revised: October 12, 2018

Accepted: October 25, 2018

\section{How to Cite}

Sushma, K. S. et al. (2018). Identification of endophytic fungi from the medicinal plants of Biligirirangana hill, Karnataka. Journal of Applied and Natural Science, 10(4): $1156-1161$ to their host against other pathogens and environmental factors (Strobel, 2003).

Endophytic fungi are the organisms which spend whole or part of its life cycle inside the healthy tissues of the host plant (Tan and Zhou, 2001). Many researchers have isolated endophytic fungi from plants for the production of natural bioactive molecules like Equisetin (Pamoda et al., 2015), Camptothecin (Pu et al., 2013).Vincristine and Vinblastine (Palem et al., 2016). (El-Hawary et al., 2016) isolated Solamargine compound from the endophytic fungus, Aspergillus flavus from Solanum nigrum plant. One notable endophyte with medicinal benefits to human was reported by Gary Strobel isolated the endophytic fungus Pestalotiopsis microspora, from Taxus wallachiana (Himalayan Yew) was found to produce Taxol, an anticancer drug (Gary et al., 1996). In the present study endophytes were isolated and identified from four medicinal plants based on the 18SrRNA sequencing and phylogentic tree, the unknown 
fungal strains have been identified.

Medicinal plants: Carica papaya commonly called papaya tree belongs to Caricaceae family. Papaya leaves contain powerful healing compounds that are very important for curing cancer and dengue fever (Paul, 2013). Hypoglycemic activity was seen in aqueous seed extract of Carica papaya in normal male wistar rats. It was found that crude extract significantly and progressively lowered fasting blood sugar, triglyceride, total cholesterol, low density lipoprotein cholesterol (LDLc) and very low density lipoprotein cholesterol (VLDL-c) dose dependent (Adeneyea and Olagunjub, 2009).

Phyllanthus amarus belongs to Phyllanthaceae family. In India, Phyllanthus amarus is widely distributed as a weed. It has been used as a herbal remedy for kidney stones, viral infections, liver disorders, and many other ailments and has valuable compounds such as lignins, flavonoids, tannins, polyphenols, triterpenes, sterols and alkaloids (Itoro et al., 2013). The compounds isolated from $P$. amarus show a wide spectrum of pharmacological activities (Patel et al., 2011) including antiviral, anti-inflammatory, anticancer, antidiabetic, nephron protective and diurectic properties (Saranraj and Sivasakthivelan, 2012). Fresh leaf paste has wound healing capacity and used to cure white spots on skin and jaundice (Sonia et al, 2014).

Tinospora cordifolia commonly known as Amruthaballi belongs to Menispermaceae family and is highly potent herb used in Ayurveda for treating diabetes. The plant contains various secondary metabolites like tinosporine, tinosporide and $\beta$ sitosterol. Phenylpropanoids, diterpene furan glycosides, diterpene furon glycosides and plytoecdysones are present in methanolic extract of plant. The bitter principle of plant has various properties like antiperiodic, anti-inflammatory antispasmodic and antipyretic properties (Savitha et al., 2012). Tribals of Korkus (Melghat, Maharashtra, India) have been using the herb for polyuria, diabetes and fever (Tambekar et al., 2009).

Azadirachta indica commonly called as Neem tree which belongs to Meliaceae family. It is one of the most effective medicinal plant in natural therapy and Ayurveda in India. Its leaves, stem, bark and seeds possess hypoglycemic activity in increasing insulin secretion from beta cells of the pancreas. Leaves are characterized by the presence of high fiber content that is potent in diabetes management and controlling of post-prandial hyperglycemia through delaying gastric emptying (Tripathi et al., 2011).

\section{MATERIALS AND METHODS}

Four medicinal plants were selected for its medicinal properties collected from the Biligirirangana Hill, located in Chamrajanagar district, South
Eastern Karnataka, India. The hill latitude ranges from $11^{\circ} 40^{\prime}$ to $12^{\circ} 09^{\prime}$ North and $77^{\circ} 05^{\prime}$ to $77^{\circ}$ $01^{\prime}$ East and covers the area of 540 sqkm.

Plant samples were brought to laboratory in polythene bags within $24 \mathrm{hrs}$. Surface sterilization was performed. The sample were washed under running tap water to remove dirt on the surface, then cut into small size segment and sequential rinsing with $70 \%$ ethanol for 30 seconds, and $0.5 \%$ sodium hypochlorite for 1 minute followed by sterile distilled water for 2-3 times and dried using sterile Whatman no. 1 filter paper The dried leaf segments were placed on petridish containing sabouraud dextrose agar (SDA) media and allowed to grow in room temperature (Schulz et al., 1993). After seven days, the emergence of fungal mycelium is examined by colony characteristics, macroscopic and microscopic observations. The unidentified fungal culture was subjected to 18SrRNA sequencing and phylogenetic analysis. Mycelia is scraped from a 10-day-old culture grown on SDA media and placed in a sterile $2 \mathrm{ml}$ Eppendorf tube. The genomic DNA is extracted from 0.5-1 g chilled mycelia in liquid nitrogen using SDS-CTAB method (Kim et al., 1990) and by using the InstaGene TM Matrix Genomic DNA isolation kit (Catalog \# 732-6030).

Target gene fragment is amplified using Thermo Scientific Veriti Thermal Cycler. DNA fragments are amplified using $1 \mu \ell$ of template DNA in $20 \mu \ell$ of total PCR reaction mixture using ITS1/ITS4 primers $(50 \mathrm{pmol})$ followed by 35 amplification cycles with denaturation at $94^{\circ} \mathrm{C}$ for 45 second, primer annealing at $52^{\circ} \mathrm{C}$ for 60 second, and extension or chain elongation at $72^{\circ} \mathrm{C}$ for 60 second. PCR products were electrophoresed in $1.2 \%(\mathrm{w} / \mathrm{v})$ agarose gels, stained with ethidium bromide and viewed under UV light to check the purity and size according to (Schoch et al., 2012). Primary PCR products showed the existence of multiple bands together. The unincorporated PCR primers and dNTPs is removed from the agarose gel with a sterile scalpel, and it is directly purified with PCR products by using Montage PCR Clean up kit (Millipore) according to the manufacturer's protocol.

The fungal isolates were identified by sequencing the translation elongation factor-1a (TEF-1 $1 \alpha)$ gene and internal transcribed spacer (ITS) regions. The fungal ITS regions are amplified by PCR using the universal primers ITS1 and ITS4 primer pairs (White et al., 1990). Sequencing reactions is performed using ABI PRISM $®$ BigDyeTM Terminator Cycle Sequencing Kits with AmpliTaq®DNA polymerase. Single-pass sequencing was performed on each template using16S rRNA gene universal primers. The fluorescent-labeled fragments are purified from the unincorporated terminators with an ethanol precipitation protocol. The samples are 
re suspended in distilled water and subjected to electrophoresis in an $\mathrm{ABI} 3730 \mathrm{xl}$ sequencer (Applied Bio systems).

Based on the bidirectional sequencing of $18 \mathrm{SrR}$ NA gene of 1400 bp the microbial communities are examined using eukaryotic and prokaryotic specific primers separately. The two samples are used to obtain $16 \mathrm{~S}$ amplicons by using prokaryotic universal primers Ribosomal RNA. ITS Region Forward Primer ITS1 (TCCGTAGGTGAACCTGCGG) and Reverse Primer ITS4 (TCCTCCGCTTATTGATATGC) $\sim 550 \mathrm{bp}$.

\section{RESULTS}

Medicinal plants Carica papaya, Phyllanthus amarus, Tinospora cordifolia, Azadirachta indica were collected from Biligirirangana hills for the isolation of endophytic fungi (Fig 1). In the present study, total fifteen endophytic fungi were isolated from the leaves of four medicinal plants and identified by colony morphology, macroscopic and microscopic observations. It was found to be Curvularia $s p$, Fusarium sp, Penicilluium sp, Colletotrichum $s p$, Aspergillus sp, Alternaria $s p$ respectively. Among the isolated fungal colony, the unidentified strain from each of the sample was subjected to molecular sequencing and phylogenetic analysis (fig 2). The identified strain were Stemphylium lycopersici, Epicoccum nigrum, Leptosphaerulina arachidicola, Phomopsis azadirachtae. (Table 1). The sequences were subjected for mega BLAST analysis (http://www.ncbi.nlm.nih.gov/), Homology was calculated by pair wise comparison of sequence from $\mathrm{NCBI}$ database and the sequences were deposited to the gene bank with the Accession number S. lycopersici- MH375406, E. nigrum - MH375409, L. arachidicola- MH250053 and P. azadirachtae- MH375411. (Table 2). The Internal Transcribed Spacer region is regarded as a DNA barcode marker for the identification of fungi, ITS region can be amplified in single PCR of 400 to $700 \mathrm{bp}$ in length $543 \mathrm{bp}$. The ITS region contains ITS1 and ITS4 that are located between the 18S and $28 \mathrm{~S}$ ribosomal subunits and the ITS1 and ITS4 regions are separated by the $5.8 S$ ribosomal RNA. 5.8S rRNA is a non-coding RNA component of the large subunit of the eukaryotic ribosome which plays an important role in protein translation.

\section{DISCUSSION}

Phomopsis sp. is an endophytic fungi that belongs to Diaporthaceae family and consists of approximately 900 species from a wide range of hosts (Udayanga et al., 2011). Several species of Phomopsis have been reported as plant endophytes. (Murali et al., 2006; Zhang et al., 2014) studied antioxidant, antifungal and cytotoxic activity of Phomopsidone and isobenzofuranones isolated
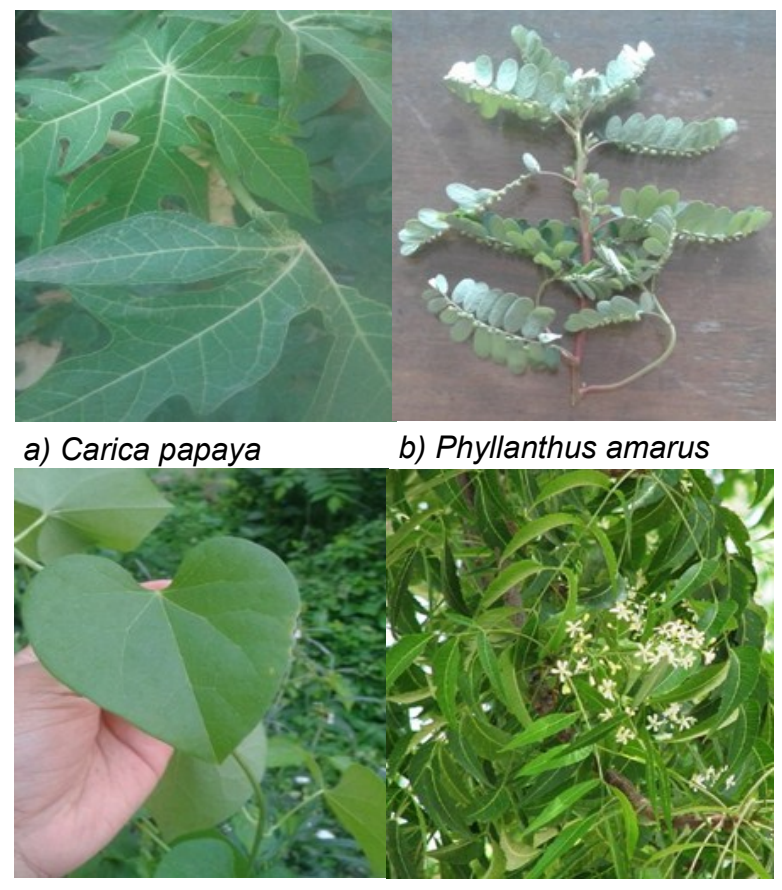

b) Phyllanthus amarus

c) Tinospora cordifolia

d) Azadirachta indica

Fig. 1. Medicinal plants collected from Biligirirangana hill.

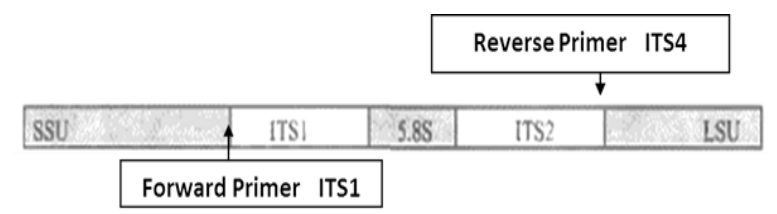

Fig. 2. Polymerase Chain Reaction.

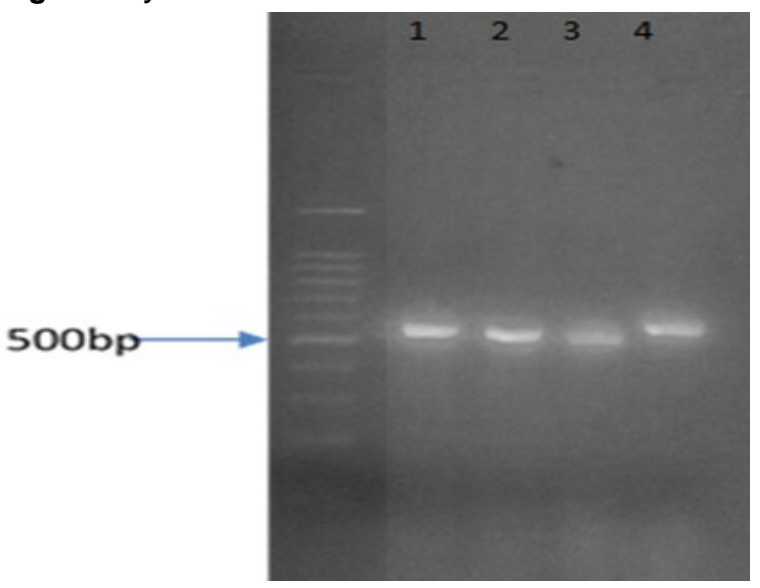

1- Stemphylium lycopersici, 2- Epicoccum nigrum, 3Leptosphaerulina arachidicola, 4- Phomopsis azadirachtae.

Fig. 3. 1\% Agarose gel data showing the band of amplified DNA.

from Phomopsis sp. (Kumaresan et al., 2014) studied the Biological activity spectrum of ethyl acetate extract of the Phomopsis $s p$ isolated from Andrographis paniculata and was analyzed in GCMS. Epicoccum sp. is a fungi belongs to Pleosporaceae family. (Fa 'varo et al., 2012) demonstrated 
Table 1. Ribosomal Gene organization and Target region amplified.

\begin{tabular}{lll}
\hline ITS Primer for Fungi & Sequence Details & Amplicon size (bp) \\
\hline Forward PrimerITS1 & TCCGTAGGTGAACCTGCGG & \\
Reverse Primer ITS4 & TCCTCCGCTTATTGATATGC & $\sim \mathbf{5 5 0 b p}$ \\
\hline
\end{tabular}

Table 2. Strains identified based on the BLAST search of NCBI Gene database.

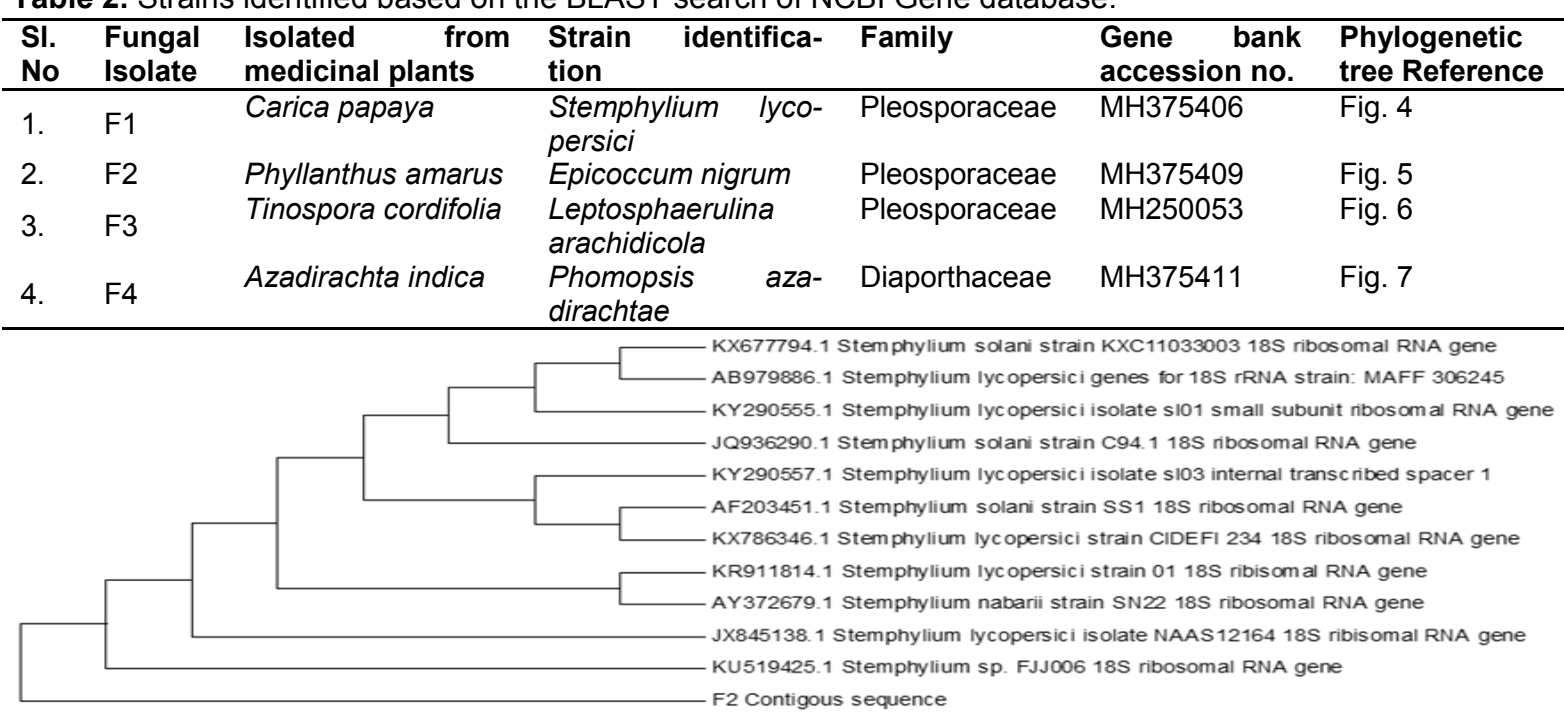

Fig. 4. F1 Fungal isolate (Stemphylium lycopersici) phylogenetic tree

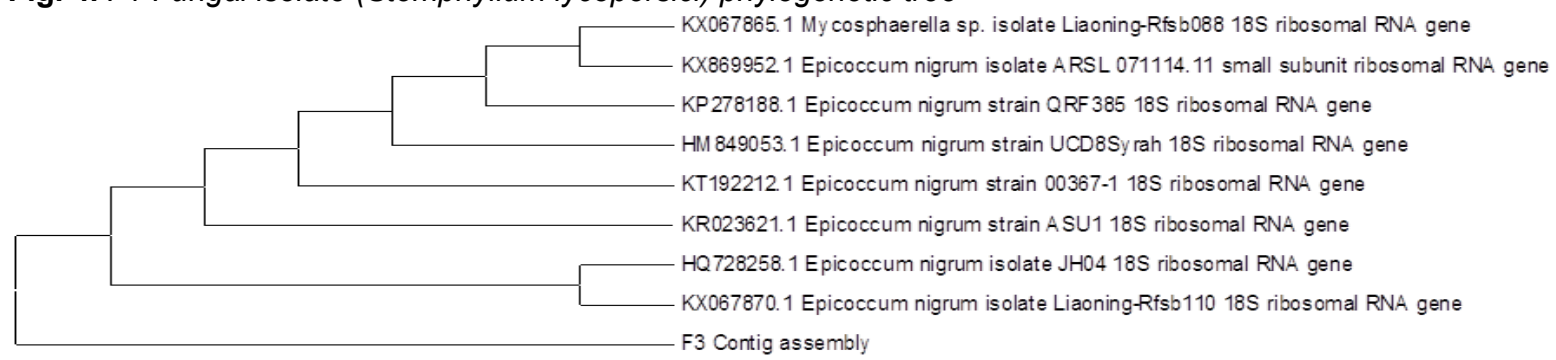

Fig. 5. F2 Fungal isolate (Epicoccum nigrum) phylogenetic tree

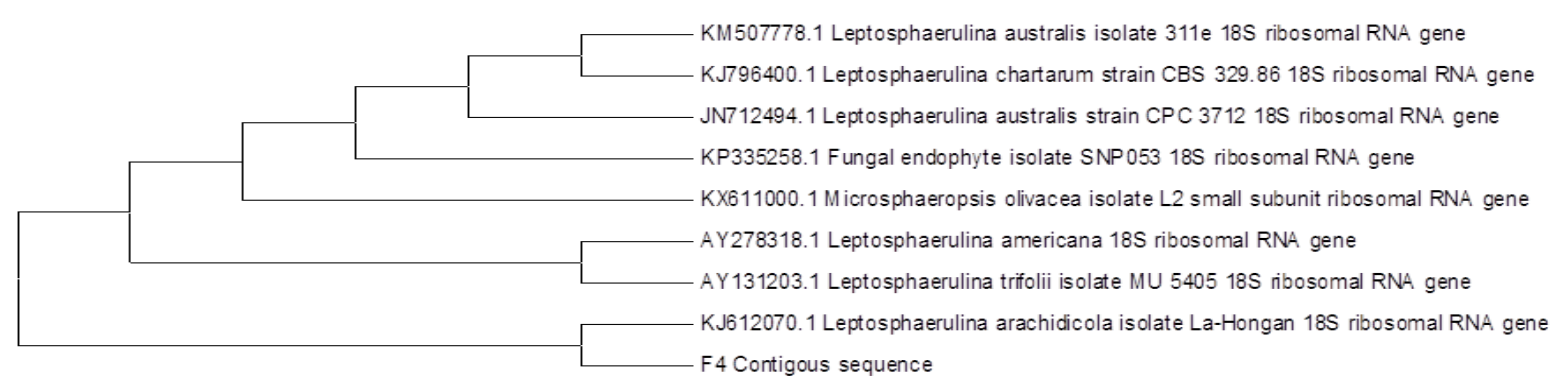

Fig. 6. F3 Fungal isolate (Leptosphaerulina arachidicola) Phylogenetic tree.

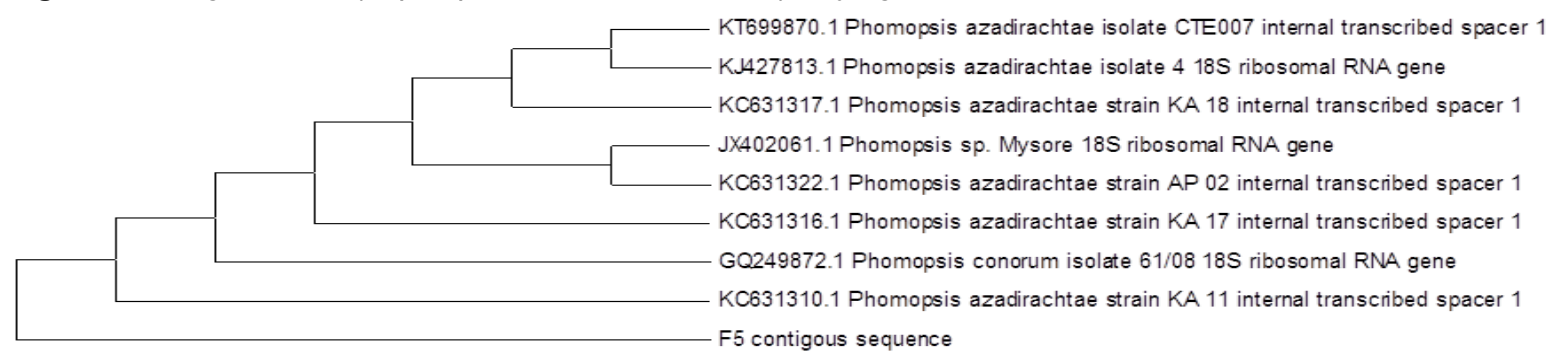

Fig. 7. F4 Fungal isolate (Phomopsis azadirachtae) Phylogenetic tree.

Figs. 4-7. Represents phylogenetic tree, reference Nucleic Acids Research Vol. 18 Supplement. Determined sequence based on the 18SrRNA. 
that $E$. nigrum has great potential for sugarcane crop application because it is capable of increasing the root system biomass and controlling pathogens. They studied the basic aspects of the interaction of ubiquitous endophyte with the host plant E. nigrum with sugarcane as a facultative endophytism for the phylloplane environment and also to a better use of microbial endophytes in agriculture.

\section{Conclusion}

Medicinal plants are one of the important natural source for curing diseases. Endophytic fungi are the found as the symbionts present internally colonizing internal tissues of the cell. Manual sequencing of $18 \mathrm{~S}$ rRNA genes is one of the most commonly used method for phylogenetic analysis to identify at species level. Phylogenic tree based on ITS region gene sequences showing relationships and the most close type strain species of four organisms based on sequence alignment and Phylogenetic analysis the identification of fungal isolates has been summarized. With this required parameters it has proposed that ITS region along with $5.8 \mathrm{~S}$ gene sequence is the standard barcode for fungal genome identification. Therefore ITS sequencing is fast and sensitive method widely used for the molecular phylogeny of the fungal genome study in a short period of time. Hence it is the most useful method for identification of fungi at species level. The organism is related species reported in this paper as a fungal endophyte, future work to be carried out for the extraction of bioactive compounds.

\section{ACKNOWLEDGEMENTS}

The authors are thankful to Mangalore University for providing the fellowship and facilities to carry out this work.

\section{REFERENCES}

1. Adeneyea, A.A., and Olagunjub, J.A. (2009). Preliminary hypoglycemic and hypolipidemic activities of the aqueous seed extract of Carica papaya in wistar rats. Biology and Medicine. 1: 1-10.

2. El-Hawary, S.S., Mohammed, R., AbouZid, SF., Bakeer, W., Ebel, R., Sayed, AM., Rateb, ME., (2016). Solamargine production by a fungal endophyte of Solanum nigrum. J Appl Microbiol., 120(4): 900-911.

3. Fa 'varo LCdL, Sebastianes FLdS, Arau 'jo WL (2012) Epicoccum nigrum P16, a Sugarcane Endophyte, Produces Antifungal Compounds and Induces Root Growth. PLoS ONE 7(6): e36826. doi:10.1371/ journal.pone.0036826

4. Gary S., Xianshu Yang., It Joe Sears., Robert Kramer., Rajinder S., Sidhu and Hess, WM. (1996). Taxol from Pestalotiopsis microspora, an endophytic fungus of Taxus wallachiana Microbiology, 142: 435440.

5. Itoro, E., Ukana, D., and Ekaete, D. (2013). Phytochemical screening and nutrient analysis of Phyl- lanthus amarus. Asian Journal of Plant Science and Research. 3: 116-122.

6. Kim, WK., Mauthe, W., Hausner, G., Klassen, GR. (1990). Isolation of high molecular weight DNA and double-stranded RNAs from Fungi. Can J Bot. 68: 1898-1902.

7. Kumaresan, S., Senthilkumar, V., Stephen, A., and Balakumar, BS., (2014). GC-MS analysis and Passassisted prediction of biological activity spectra of extract of Phomopsis sp. Isolated from Andrographis paniculata. World Journal of Pharmaceutical Research. 4(1): 1035-1053.

8. Murali, TS., Suryanarayanan, TS., Geeta, R., (2006). Endophytic Phomopsis species: host range and implications for diversity estimates. Can. J. Microbiol. 52: 673-680.

9. Palem, Kuriakose, GC., Jayabaskaran, C. (2016). Correction: An Endophytic Fungus, Talaromyces radicus, Isolated from Catharanthus roseus, Produces Vincristine and Vinblastine, Which Induce Apoptotic Cell Death. PLOS ONE 11(4): e0153111.

10.Pamoda, B., Ratnaweera, E., Dilip de, Silva., David, E.. Williams., and Raymond, J., Andersen. (2015). Antimicrobial activities of endophytic fungi obtained from the arid zone invasive plant Opuntia dillenii and the isolation of Equisetin, from endophytic Fusarium sp. Nutr Hosp., 32(6): 2932-2937 ISSN 0212 -1611.

11.Patel, JR., Tripathi, P., Sharma, V., Chauhan, NS. and Dixit, VK. (2011). Phyllanthus amarus: Ethnomedicinal uses, Phytochemistry and Pharmacology. Journal of Ethnopharmacology. 138 (2): 286-313.

12.Paul, H. (2013). Uses for Papaya Leaves - A Powerful Cure for Cancer.

13.Pu, X., Qu, X., Chen, F., Bao, J., Zhang, G., and Luo, Y., (2013). Camptothecin producing endophytic fungus Trichoderma atroviride LY357: Isolation, Identification, and fermentation conditions optimization for Camptothecin production. Appl Microbiol Biotechnol. 97(21):9365-75. doi: 10.1007/s00253-013-5163-8.

14.Saranraj, P., and Sivasakthivelan, P. (2012). Screening of antibacterial activity of the medicinal plant Phyllanthus amarus against urinary tract infection causing bacterial pathogens. Applied Journal of Hygiene. 1 (3): 19-24.

15.Savitha, D., Rita, M., Sonam, V., Varuni, Kirti, P., and Basavaraj, H. (2012). Phytochemical analysis, Antimicrobial and Antitumour screening of Endophytes of Tinospora cordifolia. Int J Pharm Bio Sci Oct; 3(4): (B) $533-540$.

16.Schoch, CL., Seifert, KA., Huhndorf, S., Robert, V., Spouge, JL., Levesque, CA., and Chen, W. (2012). Nuclear ribosomal internal transcribed spacer (ITS) region as a universal DNA barcode marker for Fungi. Proceeding of National Academy of Science USA. 109(16) 6241-6246.

17.Schulz, B., and Boyle, C. (2006). What are endophytes? In: Schulz, B., Boyle, C., Sieber, T., editors. Microbial root endophytes. Berlin: Springer-Verlag. p. $1-13$.

18.Schulz, B., Wanke, U., Drager, S., Aust, HJ. (1993). Endophytes from herbaceous plants and shrubs: Effective of surface sterilization methods. Mycological Research. 97:1447-1450.

19.Sonia, V., Hitender S., and Munish G. (2014). Journal of Pharmacognosy and Phytochemistry 3 (2): 1822.

20.Strobel, GA. (2003). Endophytes as sources of bio- 
active products. Microbes and Infection; 5:535 44.

21.Tambekar, DH., Khante, BS., Chandak, BR., Titare, AS., Boralkar, SS., and Aghadte, SN. (2009). Screening of antibacterial potentials of some medicinal plants from Melghat forest in India. Afr $J$ Tradit Complement Altern Med. 6(3): 228-232.

22.Tan, RX., and Zhou, WX. (2001). Endophytes: A rich source of functional metabolites. Nat. Prod. Rep., 18, 448-459.

23.Tripathi, AK., Bhoyar, PK., Baheti, JR., Biyani, DM., and Khalique, M. (2011). Herbal antidiabetics. International Journal Research of Pharmcological Science 2: 30-37.

24.Udayanga, D., Liu X., McKenzie EHC., Chukeatirote,
E., Bahkali, HA., Hyde, KD. (2011). The genus Phomopsis: biology, applications, species concepts and names of common phytopathogens. Fungal Diversity, 50: 189-225.

25.Valiathan, MS. (1998). Healing plants. Curr. Sci., 75:1122-1126.

26.White, TJ., Burns, T., Lee, S., and Taylor, J. (1990). Amplification and direct sequencing of fungal ribosomal RNA genes for phylogenetics. San Diego: Academic Press, 315-322.

27.Zhang, W., Xu, L., Yang, L., Huang, Y., Li, S., Shen, Y. (2014). Phomopsidone A, a novel depsidone metabolite from the mangrove endophytic fungus Phomopsis sp. A123. Fitoterapia, 96: 146-151. 